\title{
THE FAUNA OF THE MONTE BELLO ISLANDS
}

\section{A Note on the Probable Effect of the Atomic Explosion}

\section{By Surgeon Commander G. Wedd, R.N.}

The present condition of those parts of the Islands affected by the explosion, particularly of those parts with evidence of radioactive contamination, is still a secret even if fully known. Furthermore, it will be many years before the final effects of delayed radiation can be assessed; so any speculations that can be made about the survival of animal species must be very tentative ones.

It does not seem likely that the survivai of any species, which was not on the verge of extinction in any case, will have been endangered except in the event that:-

(1) The species' habitat was extremely limited and was confined to a part that has suffered most severely. This condition has not been fulfilled for any known species and is unlikely for topographical reasons.

(2) A substantial proportion of the members of a mobile species move into a radioactive area for long enough to have their genes adversely or even fatally affected. There is no special reason why they should not if they can fly, but the danger cannot be very great, for during the time when the radioactivity is at its height the region is likely to be made unattractive through the killing of vegetation and their natural prey.

The danger to migrating species must be considered imaginary rather than real. The explosion took place during the spring migration and doubtless a few migrators will have rested and possibly stayed for a few days in radioactive areas. Theoretically, adverse mutations may have been produced which, given time, could spread throughout the species. So far as I know no radiation experiments have ever been done on a wild species but on theoretical grounds the danger must be infinitesimal; in fact if there is any danger man has treated his own species far worse in this respect than this handful of migrants.

The condition of a species that is confined to a small island or group of islands is necessarily precarious but in this case I do not believe that the atom bomb was so serious a threat as the droughts to which the population is periodically exposed, and it was almost certainly less serious than the introduction of a formidable predator such as the domestic cat. 


\section{Mammals}

The marsupials seen by Montague (Proc. Zool. Soc., 1914) have now disappeared from the Monte Bello Islands, as he expected them to do in a short time, leaving as the only native mammal a small bat, Eptesicus pumilus. It is still present, for one was found on one of the ships, but it cannot be numerous as there is no record of it being seen or heard ashore. It is a widespread Australian species.

Introduced species are the domestic cat and the black rat ( $R$. rattus). As they cannot be regarded as anything but liabilities we are not concerned about their welfare, but the rat at least, which can be caught without difficulty, may be interesting for genetic observations in years to come.

\section{BirDs}

Only about fifteen species of land birds have been recorded from the Islands and most of those are migrants.

Some concern has been shown about three of the natives on the grounds that they are subspecifically different from those elsewhere or that their range is very restricted. These three are :-

(1) The Black and White Wren (Malurus leucopterus). This was found by Montague on Trimouille Island and also living on Barrow and on Dirk Hartog Island, about 300 miles south. I doubt if it was living in the Monte Bellos in 1952. It was never seen in several months of occupation, in spite of the fact that there were a number of Australians present who were familiar with the blue and white form and would hardly have missed the black and white one if it had been there.

(2) The Desert Bird (Eremiornis carteri subsp.). This is said to be subspecifically different from the rare mainland form but there is some doubt about it. Montague found it plentiful on Hermite. I doubt if it is plentiful there now as I never saw it myself, though I was looking for it, and I never heard an unmistakable description. That is not good evidence that it has disappeared for it has not a conspicuous appearance, like the wren, and it is very retiring by nature.

(3) The Monte Bello Pipit (Anthus novoe-zeelandice subsp.), said to be subspecifically different from the mainland form, is common on all the larger islands and crosses the narrow sea from one to the other. It was left in a thriving condition after the explosion and its chances must be regarded as good, though it does possibly run some slight risk of the genetic trouble already mentioned. 


\section{RePTILES}

These have not yet been fully described but it is clear that there are several species of lizards and snakes that are not common in other places. Not knowing their distribution in the islands I cannot say what their chances are likely to be.

\section{LAND INVERTEBRATES}

Many forms are apparently confined to the Islands or, at any rate, have not been recorded elsewhere. There is no exact knowledge of their habitats and one can only say that enough land to give them every chance has been left undisturbed.

\section{Marine Animals}

We are not really concerned with these since it is unlikely that any species is strictly confined to such a small area. 